УДК 316.452:005.96

\author{
Ангелов Г.В. \\ доктор философрских наук, профессор \\ E-mail: sociologia.kafedra@mail.ru \\ Черкасский A.B. \\ кандидат исторических наук, доцент \\ кафедра социологии, философии и права \\ Одесская национальная академия пищевых технологий \\ ул. Канатная, 112, г. Одесса, Украина, 65039 \\ E-mail: academy_@ukr.net
}

\title{
ПСИХОЛОГИЧЕСКИЕ ОСОБЕННОСТИ ПОДБОРА УПРАВЛЕНЧЕСКОГО ПЕРСОНАЛА В СОВРЕМЕННОЙ ПИЩЕВОЙ ОТРАСЛИ
}

В статье рассматриваются основные принципы психологического подбора и оценки управленческих кадров на предприятии, анализируются главные методики, применяемые при психологическом отборе персонала, а также качества, необходимые современному руководителю. Особый акцент сделан на психологических особенностях подбора руководящих кадров для пищевой отрасли, определены основные качества, которыми должен обладать руководитель современного пищевого предприятия.

Ключевые слова: психологический подбор, оценка персонала, управление человеческими ресурсами, диагностические методики, ценностные ориентации личности, кадровый резерв, психологическая готовность к деятельности.

Постановка проблемы и ее связь с важными научными и практическими задачами. Ключевой составляющей любого предприятия является управление кадрами. Оно обеспечивает благоприятную среду, в которой реализуется трудовой потенциал, развиваются личные способности, люди получают удовольствие от выполнения работы и общественного признания своих достижений.

От обеспечения предприятия квалифицированными кадрами, рационального их использования зависят организационно-технический уровень производства, имидж предприятия, его финансовая стабильность, все показатели деятельности предприятия. Прежде чем организация предложит комунибудь работу, она должна найти тех людей, которые хотели бы ее получить. В этом и заключается набор создать необходимый резерв кандидатов на все должности, из которых потом будут отобраны наиболее пригодные работники. То есть главная задача отбора персонала - выбор наиболее пригодных кандидатов из резерва, созданного в ходе набора. При этом используются многочисленные формы и методы отбора, с помощью которых фирмы и организации отбирают наиболее пригодных им людей.

Анализ последних публикаций по проблеме. Анализ работ в области профессионального психологического отбора (А.Д. Глоточкин, К.М. Гуре- вич, М.И. Дьяченко, Е.А. Климов, Ю.В. Котелова, Н.И. Майзель, Г.С. Никифоров, К.К. Платонов, А.Ф. Шикун, П.Я. Шлаен и др.) показал, что одним из перспективных путей проведения процедуры психологического отбора является изучение психологической готовности человека к деятельности. Психологическая готовность человека к деятельности рассматривается как особенное достаточно стойкое состояние, которое включает ряд компонентов: мотивационноориентировочный, операционный, оценочный, волевой и др.

Отечественные психологи часто обращаются к проблеме профессионально-психологического отбора, так например, концептуальные, организационно-практические и этические ориентиры работы с персоналом были освещены в работах Г.С. Никифорова, Т.С. Кабаченко, Т.И. Саксакулма, Е.В. Таранова, А.А. Крылова, А.И. Юрьева. Такие ученые, как Е.А. Климов, К.М. Гуревич., О.Н. Батькивщина, М.А. Дмитриева, Е.М. Иванова, Б.В. Кулагин, С.А. Маничев, С.И. Симоненко, Г.П. Логинова, М.О. Мдивани, А.А. Фрумкин, Т.П. Зинченко, Л.В.Винокуров уделяли внимание анализу профессиональной деятельности и психодиагностики персонала. Мотивационные особенности в деятельности персонала рассмотрены в работах Е.П. Ильина, А.Л. Журавлева, А.А. Сарно, 
В.М. Князева, В.Г. Асеева, А.В. Рыжова, А.Л. Свенцицкого.

Из работ зарубежных учёных научный интеpec, на наш взгляд, представляет собой известное широкому кругу специалистов в области менеджмента исследование Джима Коллинза «От хорошего к великому» (JIM COLLINS «GOOD TO GREAT») [7]. Д. Коллинз размышляет о роли руководителя, который способен осуществлять преобразования, о том, всегда ли успех выдающихся компаний основан на применении новых технологий. Значительный интерес представляет книга «Оценка персонала: как управлять человеческим капиталом, чтобы реализовать стратегию», написанная в соавторстве - Марк А. Хьюзилид, Брайан Е. Беккер, Ричард У. Битти Ю. В ней сделан акцент на то, что инвестиции в трудовые ресурсы должны способствовать реализации стратегии организации через ее культуру, образ мышления, способности и соответствующие поведенческие модели ее сотрудников [10]. Общие вопросы управления трудовыми ресурсами рассматриваются в книге авторов Майкла Мескона, Майкла Альберта, Франклина Хедоури «Основы менеджмента» [8] и в книге Бреддика У. «Менеджмент организации» [3].

Сущностью психологического компонента профессионального отбора, равно как и его теоретической основой, является диагностика и прогнозирование способностей. По этой причине, в частности, понятие "профессиональный отбор" и "психологический отбор" часто отождествляются. Психологический отбор целесообразно рассматривать как процесс и как систему.

Основными этапами процесса психологического отбора являются: исключение и первичная обработка необходимой исходной диагностической информации; формулировка прогнозов способности к данному виду профессиональной деятельности и оценка предсказуемого уровня пригодности обследуемых; верификация прогнозов на основе данных о фактической эффективности профессиональной деятельности отобранных лиц.

Система психологического отбора должна включать обоснованный и экспериментально проверенный комплекс социальных диагностических методик, необходимых технических средств и стандартизированную процедуру обследования; приемы обобщения, интерпретации исходной диагностической информации и складывания прогнозов; показатели профессиональной эффективности и критерии оценки успешности деятельности; логические и математические аппараты верификации прогнозов.
Основным принципом использования в системах психологического отбора существующих диагностических методик и конструирования новых должна быть их нацеленность на диагностику ведущих наиболее стойких компонентов исследуемой способности в их структурной и функциональной взаимосвязи.

Получение информации социально-психологического порядка, который характеризует ценностные ориентации личности, мотивационную стабильность выбора профессии, личностные черты и особенности жизненного опыта, существенно расширяет возможности личностно-структурного и динамического анализа всей совокупности информации, тем самым позволяя повысить степень вероятности и надежности прогнозов.

Формулирование целей исследования. Проанализировать и выяснить основные психологические особенности и черты методов оценки и отбора управленческого персонала предприятий пищевой отрасли.

Изложение основных результатов и их обоснование. Подбор персонала - процесс изучения психологических и профессиональных качеств работника с целью установления его пригодности для выполнения обязанностей на конкретном рабочем месте или должности и выбора из совокупности претендентов тех, кто наиболее удовлетворяет организацию, с учетом соответствия его квалификации, специальности, личных качеств и способности выполнять ту или иную работу, учитывая интересы организации и его самого.

Подбор кадров на замещение должностей руководителей и специалистов обычно осуществляется или путем повышения в должности работников своего предприятия (иногда после соответствующей учебы) из числа работников, зачисленных в резерв на выдвижение, или путем приема кандидатов на эти должности извне, из других предприятий, организаций.

Выдвижение в резерв руководящих кадров стимулирует повышение творческой активности работника и это необходимо учитывать при планировании и организации работы с резервом по его подготовке и учебе. При подборе кандидатов для включения их в резерв на выдвижение, а также и при организации учебы резерва целесообразно пользоваться разработанными квалификационными моделями разных уровней руководителей, профессиограммами, перечнем требований, которые предъявляются к руководителям на современном этапе развития экономики страны. 
Наиболее приемлемым на практике является путь замещения кадров руководителей и специалистов за счет выдвижения работников своего предприятия. Он дает возможность всесторонней проверки пригодности кандидата к новой должности, подготовки его к выполнению функциональных обязанностей в новой должности. В этом случае кандидату легче войти в курс жизни коллектива и решаемых им задач. Известны и позитивные качества и определенные недостатки кандидата, что расширяет возможности их учета, особенно при подборе кандидатов на руководящую должность.

Те же качества, свойственные кандидатам извне, не всегда в полной мере известны руководителю и коллективу данного предприятия. Необходимо также иметь в виду, что выдвижение своих работников на высшие должности способствует стабильности кадров, создает уверенность у членов коллектива в возможности роста по службе на своем предприятии. В то же время подбор кандидатов на замещение должностей извне, с другого предприятия или организации способствует приливу новых людей, и, если это передовые предприятия - передового опыта, свежих мыслей.

Но назначение кандидата извне будет правильно понято коллективом только в том случае, если он будет выгодно отличаться по своим деловым качествам от кандидатов - работников данного предприятия. Поэтому подбор и назначение на должности руководителей кандидатов с других предприятий и организаций, как правило, должны происходить путем выборов на конкурсной основе[5, с. 219-223].

Стоит обратить внимание также на вопросы, связанные с изучением пригодности кандидата на должность, которая замещается. Пригодность кандидата на должность определяется в первую очередь его отношением к этой должности, наличием соответствующих знаний, умений, навыков, а в иных случаях и наличием у него соответствующих психофизиологических качеств.

Практика хозяйственного управления в Украине предъявляет высокие требования к личности руководителя, к качествам его характера, его организаторским способностям. К основным интегральным чертам личности, позволяющим эффективно руководить производственным коллективом, относятся: умение влиять на подчинённых, уверенность в себе, предусмотрительность, надёжность и ответственность при выполнении задания, независимость и др. [6, с. 350]. Многие исследователи к таким интегральным характеристикам также относят: адаптационную мобильность, эмоциональное лидерство, деловое (инструментальное) лидерство, способность к интеграции социальных функций (ролей), контактность, стрессоустойчивость.

Практика подбора и деловой оценки управленческих кадров на сегодня насчитывает более двух десятков методов, которые можно разделить на три группы: качественные, количественные и комбинированные. На наш взгляд, наиболее обоснованные пути подбора руководящих кадров состоят в использовании комплекса методов, среди которых следует выделить:

- наблюдение и анализ конкретной деятельности руководителя;

- опрос-анкетирование для выявления самооценки лидера и его оценки группой;

- естественный эксперимент - метод решения совместных задач (деловые игры);

- экспертные оценки специалистов по управлению;

- психологическое тестирование с использованием интеллектуальных, личностных и профессиональных тестов;

- социометрия с целью установления престижа в группе и психологической совместимости;

- биографический метод (изучение документации, анализ личности) [1, с.128].

Наиболее распространенным методом экспериментального исследования личности, ее качеств и способностей является метод тестовых испытаний [2].

При подборе управленческих кадров для пищевой отрасли необходимо учитывать такие качества руководителя, как способность к изменениям, так как основной задачей системы управления персоналом на предприятиях пищевой промышленности является сохранение команды, которая должна быть адаптирована к разного рода изменениям (изменениям вида деятельности, продукта, услуги). Способность или неспособность производителей пищевой продукции эффективно работать зависит именно от желания и ориентированности команды на изменения [9].

Современные предприятия пищевой промышленности представляют сложные социотехнические системы. Возрастание роли социальных и психологических ее составляющих обусловливает необходимость комплексного подхода к организации эффективной кадровой политики.

Основной первоочередной задачей руководители предприятий пищевой промышленности видят 
создание технологического, системного управления персоналом на своих предприятиях.

Кроме того, руководители отмечают необходимость корректировки системы управления персоналом в соответствии со стадиями жизненного цикла, на которых находятся предприятия. Такая необходимость возникла из-за нестабильности экономической ситуации в стране, из-за того, что предприятия пищевой промышленности уязвимы, подвластны влиянию экономических кризисов, давлению конкуренции, следовательно, система управления персоналом должна быть особенно гибкой, а персонал - готовым к изменениям.

Успех работы предприятия в условиях рынка, в конечном счете, определяется готовностью руководителя к инновационной деятельности. От этого его качества зависит выживаемость предприятия и социально-экономическое положение коллектива. Поэтому в современных условиях руководитель предприятия должен быть истинным инноватором, опирающимся в своей деятельности на достижения науки, научные разработки, быть способным оценивать и без промедления внедрять в производство инновационные идеи.

Основными приоритетами в создании системы управления персоналом являются направления мотивации сотрудников, регулирования трудовых отношений. Однако присутствующие в западной модели направления отбора, ориентации, оценки, повышения квалификации персонала пока отсутствуют на отечественных предприятиях пищевой промышленности или осуществляются спонтанно, не системно. Такая ситуация вызывает ряд проблем, связанных с отбором, учебой, увольнением персонала, психологическим климатом в коллективе-команде, лидерством, мотивацией персонала. Проблема мотивации стоит на предприятиях пищевой промышленности особенно остро, потому что почти каждый сотрудник находится на виду, часто является единственным специалистом в определенном направлении. Чтобы работа сотрудника в команде была наиболее эффективной, он должен быть заинтересован в ней морально и материально.

Современное производство предъявляет высокие требования к деловым качествам руководителя, требует от него глубоких знаний и разносторонней подготовки. Он должен быть хорошо осведомлен в вопросах техники, технологии, организации производства и труда, должен знать содержание и характер труда работников управленческого аппарата, занятых планово-экономической, снабженческо-сбытовой, учетно-аналитической, обслуживающей и другой деятельностью. В руководителе должны сочетаться такие качества, как умение применять знания на практике, хорошее аналитическое мышление, интуиция, сильная воля, решительность, смелость, знание психологии людей, деликатность, гибкость поведения.

Выводы и перспктивы дальнейших исследований. Сегодня квалифицированный специалист, занятый управленческой деятельностью, является огромной ценностью. От того, как он осуществляет организационную и технологическую подготовку производства, оперативное регулирование деятельности производственных подразделений и отдельных исполнителей, зависит производительность труда, эффективность использования производственных фондов, себестоимость продукции [4]. Следовательно, характер деятельности руководителя очень разнообразен. Он выступает в роли организатора, специалиста, администратора, общественного деятеля и воспитателя. Выполняя организационно-административные функции, управленцы занимаются поиском и подготовкой новых решений.

\section{Литература}

1. Ангелов Г. В. Психологические методы исследования личности в системе управления / Г. В. Ангелов, А. В. Черкасский // Проблеми емпіричних досліджень у психології. Вип.11 - К. : Гнозис , 2014 - 436 с.

2. Большая энциклопедия психологических тестов. - М. : Эксмо, 2009. - 416 с.

3. Бреддик У. Менеджмент организации. / У. Бреддик. - М. : «Инфра-М», 1997 г.

4. Василенко Б. І. Організація праці апарату управління / Б. І. Василенко // Підвищення діяльності підприємств харчової та переробної галузей АПК : Матеріали II Всеукраїнської науково-практичної конференції, Київ, 21-22 листопада 2013 р. : Тези доповідей. - К. : НУХТ, 2013.

5. Виноградский Н. Управление персоналом : учебное пособие. / Н. Виноградский, С. Беляева, А. Виноградская, Е. Шканова. - К., 2013.

6. Гулавский В. Т. Этический фактор в сфере труда и социального управления / В. Т. Гулавский, Е. Б. Козак, Ю. Г. Неустроев и др. / под общ.ред. проф. Г. В. Ангелова. - Одесса. : КП ОМД, 2010. - 596 с.

7. Джим Коллинз «От хорошего к великому» (JIM COLLINS «GOOD TO GREAT»). - Стокгольмская школа экономики в Санкт-Петербурге, 2006 г. 
8. Майкл Мескон. Основы менеджмента / Майкл Мескон, Майкл Альберт, Франклин Хедоури.Издательство Дело, 1994 г.

9. Москаленко В. О. Кадровий потенціал підприємств харчової промисловості України: формування, управління та розвиток : монография. / В. О. Москаленко. - К., 2010.

10. Марк А. Хьюзилид. Оценка персонала: как управлять человеческим капиталом, чтобы реализовать стратегию. / Марк А. Хьюзилид, Брайан Е. Беккер, Ричард У. Битти Ю. - М. : Издательство «И. Д. ВильямС», 2007 г.

Статья поступила 25.06.2015

\author{
Ангєлов Г.В. \\ доктор філософських наук, професор \\ E-mail:sociologia.kafedra@mail.ru \\ Черкаський А.B. \\ кандидат історичних наук, доцент \\ кафедра соціології, філософрії і права \\ Одеська національна академія харчових технологій \\ вул. Канатна, 112, м. Одеса, Україна, 65039 \\ E-mail: academy_@ukr.net
}

\title{
ПСИХОЛОГІЧНІ ОСОБЛИВОСТІ ПІДБОРУ УПРАВЛІНСЬКОГО ПЕРСОНАЛУ В СУЧАСНІЙ ХАРЧОВІЙ ГАЛУЗІ
}

У статті розглядаються основні принципи психологічного підбору та оцінки управлінських кадрів на підприємстві, аналізуються головні методики, що застосовуються при психологічному відборі персоналу а також якості, необхідні сучасному керівникові. Особливий акцент зроблено на психологічних особливостях підбору керівних кадрів для харчової галузі, визначено основні якості, якими повинен володіти керівник сучасного харчового підприємства.

Підбір персоналу - процес вивчення психологічних і професійних якостей працівника з метою встановлення його придатності для виконання обов'язків на конкретному робочому місці або посаді $\mathrm{i}$ вибору з сукупності претендентів тих, хто найбільш задовольняє організацію з урахуванням відповідності його кваліфікації, спеціальності, особистих якостей і здатності виконувати ту чи іншу роботу, враховуючи інтереси організації та його самого. Успіх роботи підприємства в умовах ринку, в кінцевому рахунку, визначається готовністю керівника до інноваційної діяльності. Від цієї його якості залежить виживання підприємства і соціально-економічне становище колективу. Тому в сучасних умовах керівник підприємства повинен бути істинним інноватором, що спирається у своїй діяльності на досягнення наук.

Сучасне виробництво пред'являє високі вимоги до ділових якостей керівника, вимагає від нього глибоких знань і різнобічної підготовки. Він повинен бути добре обізнаний в питаннях техніки, технології, організації виробництва і праці, повинен знати зміст і характер праці працівників управлінського апарату, зайнятих планово-економічною, постачальницько-збутовою, обліково-аналітичною та іншою діяльністю. У керівника повинні поєднуватися такі якості, як уміння застосовувати знання на практиці, хороше аналітичне мислення, інтуїція, сильна воля, рішучість, сміливість, знання психології людей, делікатність, гнучкість поведінки.

Ключові слова: психологічний підбір, оцінка персоналу, управління людськими ресурсами, діагностичні методики, ціннісні орієнтації особи, кадровий резерв, психологічна готовність до діяльності. 


\author{
Angelov G.V. \\ Doctor of philosophy, Professor \\ E-mail:sociologia.kafedra@mail.ru \\ Cherkassky A.V. \\ Ph.D., Associate Professor \\ department of sociology, of philosophy and right \\ Odessa National Academy of Food Technologies \\ Kanatna Street, 112, Odessa, Ukraine, 65039 \\ E-mail: academy_@ukr.net
}

\title{
PSYCHOLOGICAL FEATURES OF SELECTION OF MANAGERIAL STAFF ARE IN MODERN FOOD INDUSTRY
}

This article discusses the basic principles of psychological selection and assessment of managerial staff in the company, analyzed the main methods used in psychological selection of staff and the quality used, you must modern manager. Particular emphasis is placed on the psychological aspects of executive search for the food industry, the basic qualities that should have a head of a modern food enterprise. Recruitment - the process of studying the psychological and professional qualities of the employee to determine his fitness for duty in a particular workplace or office and choose from a set of candidates those who are most satisfied with the organization of compliance with his or her qualifications, specialties, personal qualities and the ability to perform one or another job, taking into account the interests of the company and himself. The success of the enterprise in the market, ultimately determined by the willingness of managers to innovate. From this it depends on the quality of the survival of enterprises and the socio-economic situation of the group. Therefore, in modern conditions the head of the enterprise should be a true innovator, base their activity on the achievements of science. Modern production makes high demands of the managerial competencies required of him deep knowledge and comprehensive training. He should be well versed in the art, technology, organization of production and labor, must know the content and character of employees of administrative personnel employed economic planning, supply and marketing, accounting and analytical serving and other activities. The leader should combine qualities such as the ability to apply knowledge in practice, good analytical thinking, intuition, a strong will, determination, courage, knowledge of human psychology, sensitivity, flexibility behavior.

Keywords: psychological selection, personnel evaluation, human resource management, diagnostic methods, value orientation of personality, talent pool, psychological readiness for activity.

\section{References}

1. Angelov G., Cherkassky A. (2014). Psihologicheskie metodyi issledovaniya lichnosti v sisteme upravleniya. Problemi empirichnih doslidzhen u psihologiyi. Vip. 11. Kiev: Gnozis.

2. Bolshaya entsiklopediya psihologicheskih testov. (2009). Moscow: Eksmo.

3. Breddik U. (1997). Menedzhment organizatsii. Moscow: «nfra-M».

4. Vasilenko B. (2013). Organizatsiya pratsi aparatu upravlinnya // Pidvischennya efektivnosti diyalnosti pidpriemstv harchovoyi ta pererobnoyi galuzey APK: Materiali II Vseukrayinskoyi naukovo-praktichnoyi konferentsiyi, Kiyiv, 21-22 listopada 2013 r.: Tezi dopovidey. Kiev: NUHT. posobie. Kiev.

5. Vinogradskiy N., Belyaeva S., Vinogradskaya A., Shkanova E. (2013). Upravlenie personalom: uchebnoe

6. Gulavskiy V., Kozak E., Neustroev Y., Palamarchuk V., Petrakova E., Cherkassky A., Angelov G. (2010). Eticheskiy faktor v sfere truda i sotsialnogo upravleniya / pod obsch. red. prof. G.V. Angelova. Odessa: KP OMD.

7. Kollinz D. (2006). «Ot horoshego k velikomu» (JIM COLLINS «GOOD TO GREAT»). Stokgolmskaya shkola ekonomiki v Sankt-Peterburge.

8. Meskon M., Albert M., Hedouri F. (1994). Osnovyi menedzhmenta. Moscow: Izdatelstvo Delo.

9. Moskalenko V. (2010). Kadroviy potentsIal pidpriemstv harchovoyi promislovosti Ukrayini: formuvannya, upravlinnya ta rozvitok: monografiya. Kiev.

10. Mark A. Hyuzilid, Brayan E. Bekker, Richard U. Bitti Yu. (2007). Otsenka personala: kak upravlyat chelovecheskim kapitalom, chtobyi realizovat strategiyu. Moscow: Izdatelstvo «I.D. Vilyams». 